\title{
Doppler velocimetry in fetal rats exposed to enoxaparin and unfractionated heparin (UFH) during pregnancy ${ }^{1}$
}

\author{
Flavio Renato de Almeida Senefonte', Ricardo Dutra Aydos", Vanessa Marcon de Oliveira"I', Marco \\ Antonio Costa Bósioiv, Ernesto Antonio Figueiró-Filhov
}

'Fellow PhD degree, Postgraduate Program in Health and Development, Universidade Federal de Mato Grosso do Sul (UFMS), Campo Grande-MS, Brazil. Conception, design, intellectual and scientific content of the study; technical procedures; acquisition and interpretation of data; statistical analysis; manuscript writing; critical revision.

"PhD, Associate Professor, Department of Surgery, UFMS, Campo Grande-MS, Brazil. Intellectual and scientific content of the study, critical revision, final approval.

I'IPhD, Pharmacist, Centro de Ciências Biológicas e da Saúde, UFMS, Campo Grande-MS, Brazil. Technical procedures, acquisition and interpretation of data.

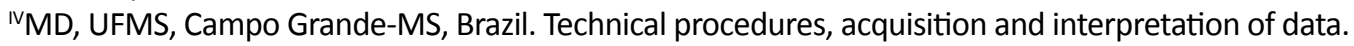

VPhD, Associate Professor, UFMS, Campo Grande-MS, Brazil. Conception, design, intellectual and scientific content of the study; critical revision; final approval.

\begin{abstract}
Purpose: To evaluate the effects of enoxaparin and unfractionated heparin (UFH) administered in prophylactic and therapeutic doses on fetal vessels in healthy pregnant Wistar rats, according to Doppler velocimetry measurements.

Methods: Fifty animals were assigned to one of five groups: controls (saline), prophylactic and therapeutic enoxaparin ( 1 and $2 \mathrm{mg} / \mathrm{kg} /$ day, respectively), and prophylactic and therapeutic UFH (72 and $400 \mathrm{UI} / \mathrm{kg} /$ day, respectively). Uterine horns were examined by ultrasound for identification of live fetuses. A sample of these fetuses underwent Doppler velocimetry. Spectral curves, peak systolic velocity (PSV), pulsatility index (PI), and resistance index (RI) of the middle cerebral artery, ductus venosus, and umbilical artery were investigated. Differences were considered statistically significant when $p<0.05$.

Results: No significant differences in PSV, PI, or RI values were observed among the groups.

Conclusion: Doppler velocimetry measurements revealed no significant effects of enoxaparin or unfractionated heparin on fetal vessels in pregnant Wistar rats.
\end{abstract}

Key words: Ultrasonography, Doppler. Middle Cerebral Artery. Uterine Artery. Heparin. Anticoagulants. Rats. 


\section{Introduction}

Thromboembolic events are the principal cause of maternal mortality. Administration of anticoagulants during pregnancy, particularly at prophylactic doses in patients with previous miscarriage or fetal loss, proven thrombophilia, or a history of venous thromboembolism, has increased over the past decades. Risks, however, cannot be ruled out, and most side effects of anticoagulant administration have been documented. Heparins are recognized as the safest anticoagulant agents ${ }^{1-5}$.

Experimental studies of heparin administration during pregnancy have revealed improved uteroplacental modulation, invasion, and adhesion, with lower rates of fetal loss, miscarriage, and pre-eclampsia ${ }^{6-7}$.

Ultrasonography is an important routine prenatal examination, providing morphological and physiological investigation, particularly with the echo-Doppler technique. Doppler velocimetry (also known as Doppler flowmetry) of fetal circulation is a highly useful tool for screening, as well as for probing for pre-eclampsia predictors, intrauterine growth restriction, fetal distress, and the likelihood of genetic abnormalities such as aneuploidy².

Given the widespread use of ultrasonography in the first trimester of pregnancy, fetal exposure to Doppler has been increasingly investigated for its safety and bioeffects ${ }^{3-5}$. Good placental formation and fetal oxygenation can be predicted using Doppler velocimetry to evaluate resistance and pulsatility indices and spectral waveforms of uterine arteries, umbilical arteries, ductus venosus, and the middle cerebral artery ${ }^{2,8,9}$.

The purpose of the present study was to evaluate patterns observed in pulsed Doppler velocimetry after exposure to unfractionated heparin (UFH) and low-molecular-weight heparin in pregnant Wistar rats.

\section{- Methods}

Guidelines for care and use of laboratory animals were fully complied with. The study was approved by the Ethics Committee on Animal Use of the Universidade Federal de Mato Grosso do Sul (permit 282, issued March 11, 2011).

This experimental study, conducted at the Laboratory of Surgical Techniques of the Universidade Federal de Mato Grosso do Sul, Campo Grande-MS, included 50 female adult Wistar rats weighing $160-300 \mathrm{~g}$. On day 0 of pregnancy, the animals were randomly assigned to one of five groups to receive the following subcutaneous treatments: saline (group I, controls), prophylactic enoxaparin at $1 \mathrm{mg} / \mathrm{kg} /$ day (group II), therapeutic enoxaparin at $2 \mathrm{mg} /$ $\mathrm{kg} /$ day (group III), prophylactic UFH at $72 \mathrm{UI} / \mathrm{kg} /$ day (group IV), or therapeutic UFH at $400 \mathrm{IU} / \mathrm{kg} /$ day (group V).

The animals were housed in cages at suitable temperature and humidity. The shelves were kept under a natural light-dark cycle and brightness was controlled in the facility. Food and water were provided ad libitum before and throughout the pregnancy period.

Once housed with males, the females were considered pregnant (day 0 of pregnancy) when sperm was found in vaginal smears, which were taken daily.

Fetal ultrasonography was performed on day 18 of pregnancy. To this end, the females were intraperitoneally anesthetized with xylazine (5-10 mg/kg) and ketamine $(50-75 \mathrm{mg} /$ $\mathrm{kg}$ ) and had their abdomens shaved.

\section{Ultrasonography}

Ultrasound examination employed a Toshiba SSA-660A Xario device equipped with a 4.8-11 MHz multifrequency linear probe. An axial section at the top of the maternal pelvis was initially examined, and the probe was then moved cranially toward the bladder until the uterine horns and fetuses were located and 
identified. Fetal viability was confirmed. The first and last fetuses in each uterine horn, in addition to a randomly chosen intermediate fetus, were selected for examination (Figure 1).

\section{Fetus in uterine horn}

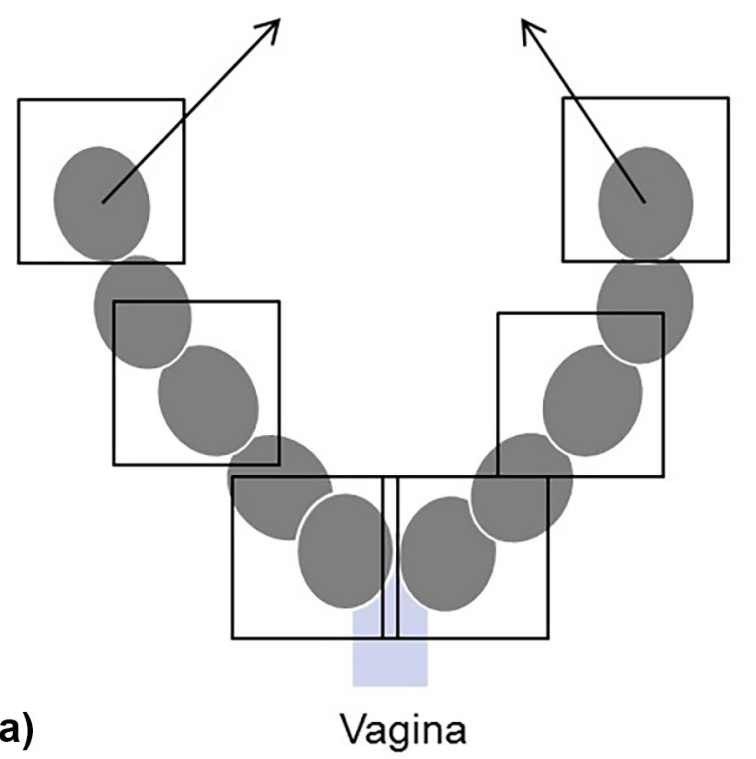

b)

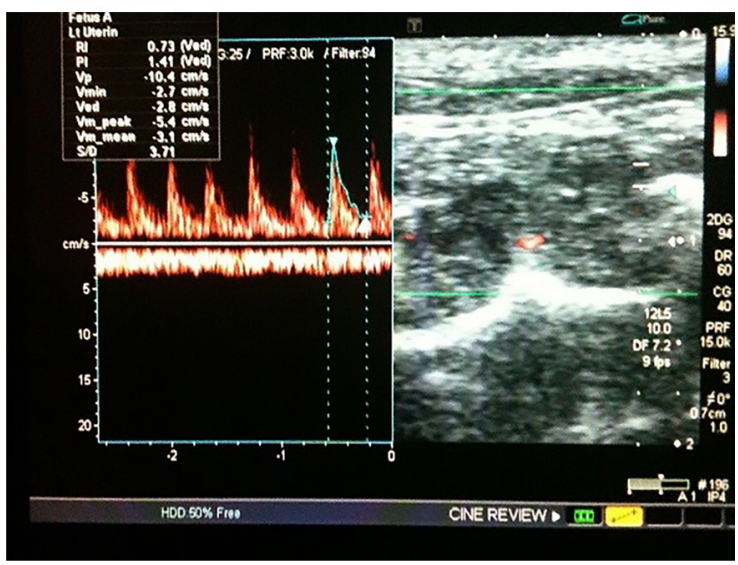

Figure 1 - (a) Study design. Fetus sampling in uterine horns. The first, the last, and an intermediate fetus were selected in each uterine horn. (b) Example of pulsed Doppler uterine artery waveform.

In each fetus, a sagittal view was used to identify the middle cerebral artery, ductus venosus, and umbilical artery by analyzing a sample volume in color mode and spectral mode, followed by pulsed Doppler.

Continuous, pulsed, color, and Power Doppler modes were employed. All examinations were conducted by the same observers.

Pulsed Doppler exposure was performed at a frequency of $6.2 \mathrm{MHz}$ and a frame rate of 19.5. Two-dimensional gain was set at $90 \%$, color gain at 40\%, and PRF between 10 and $15 \mathrm{~cm} / \mathrm{s}$. Sample volume was $0.5 \mathrm{~mm}$. The insonation angle was kept at $<30^{\circ}$.

The middle cerebral artery, ductus venosus, and umbilical artery were recognized based on blood flow waveforms of the sample, detected in color mode for brain, liver, and ventral scans. After vessel identification, speed curve measurements - peak systolic velocity (PSV), pulsatility index (PI), and resistance index (RI)-were automatically obtained.

On day 20 of pregnancy, the animals were submitted to euthanasia (toxic anesthetic dose), followed by median laparotomy and fetal and placental removal. Maternal weight was measured and the fetuses counted and individually weighed (Figures 2 and 3).

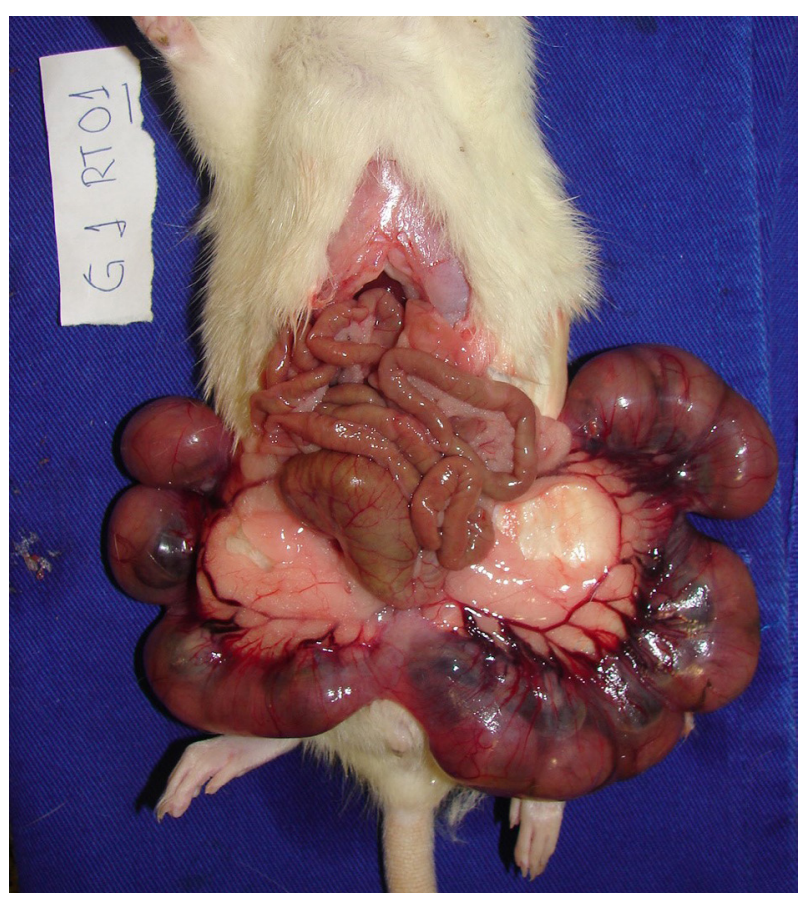

Figure 2 - Uterine horns, with fetuses and placentas, on day 20 of pregnancy. 


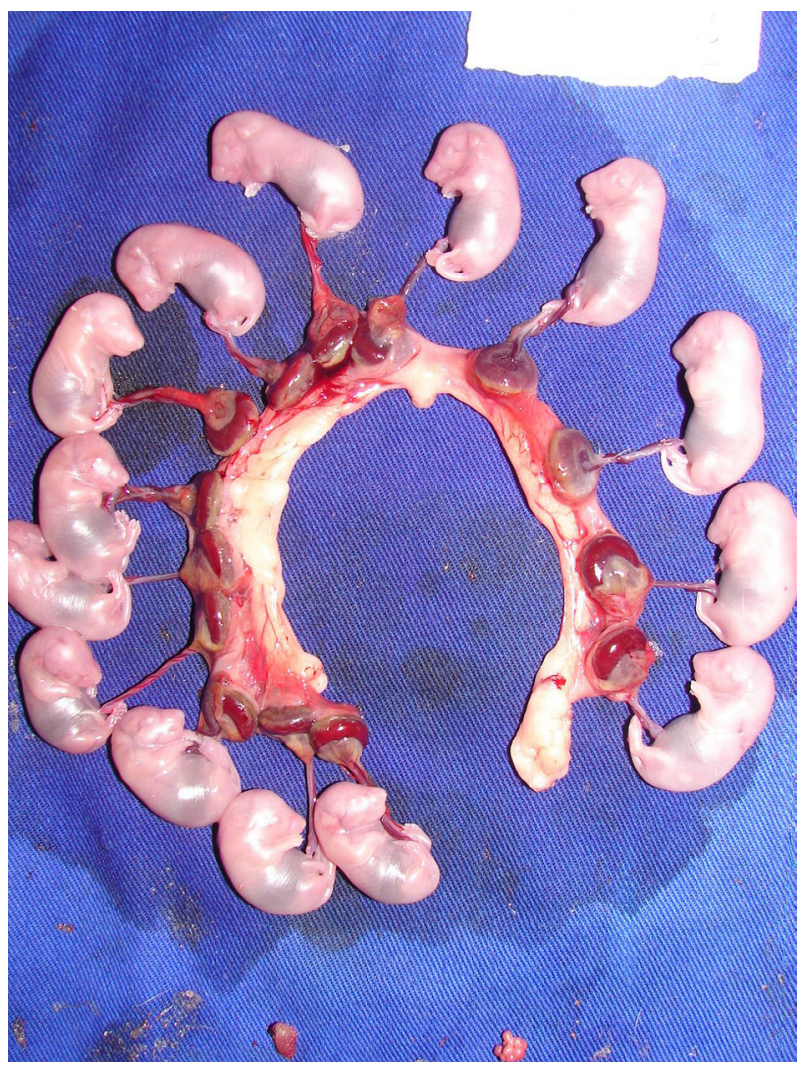

Figure 3 - Open uterine horns, showing fetuses, placentas, and implantation sites on day 20 of pregnancy.

\section{Statistical analysis}

Quantitative data were examined for normality using the Shapiro-Wilk test. Data exhibiting normal distribution were expressed as means \pm standard deviations, and otherwise as medians \pm interquartile differences.

Weight of pregnant animals, number of fetuses, and PSV, PI, and RI values were subjected to Student's t-test for comparisons between groups. For data with normal distribution and similar variances, ANOVA was employed to compare three or more groups for the same variables.

The Mann-Whitney test was used to compare medians between two independent samples, and Kruskal-Wallis to compare medians among three or more independent samples, with Dunn's post-test performed when $p$-values proved significant.

Differences were considered statistically significant when $p<0.05$.

GraphPad Prism software, version 3.00, was used for all statistical calculations.

\section{Results}

No technical difficulties occurred during vessel insonation. The acoustic window was adequate, with excellent bilateral visualization of vessels in $100 \%$ of cases. Mean time of examination was 37.3 \pm 12.1 minutes per pregnant rat, with no significant differences among the groups.

No curves with zero or reverse diastoles were observed.

Comparisons between experimental groups and control group, as well as across groups, revealed no significant differences in the mean numbers of fetuses per female, per uterine horn, or between left and right uterine horns (Table 1).

Table 1 - Fetuses per female and per uterine horn on day 21 of gestation.

\begin{tabular}{lcccc} 
Group & $\begin{array}{c}\text { Fetuses per female } \\
\text { (mean } \pm 1 \text { SD) }\end{array}$ & $\begin{array}{c}\text { Fetuses per right } \\
\text { uterine horn } \\
\text { (mean } \pm 1 \text { SD) }\end{array}$ & $\begin{array}{c}\text { Fetuses per left } \\
\text { uterine horn } \\
\text { (mean } \pm 1 \text { SD) }\end{array}$ & p $^{*}$ \\
\hline I: Control & $12.82 \pm 2.34$ & $6.32 \pm 0.24$ & $6.18 \pm 0.37$ & - \\
II: Enoxaparin, prophylactic dose & $11.98 \pm 1.78$ & $6.05 \pm 0.41$ & $5.98 \pm 0.23$ & $n s$ \\
III: Enoxaparin, therapeutic dose & $12.23 \pm 1.94$ & $6.17 \pm 0.35$ & $6.21 \pm 0.25$ & $n s$ \\
IV: UFH, prophylactic dose & $12.57 \pm 2.03$ & $6.12 \pm 0.17$ & $6.14 \pm 0.34$ & $n s$ \\
V: UFH, therapeutic dose & $12.34 \pm 1.56$ & $6.25 \pm 0.14$ & $6.08 \pm 0.18$ & $n s$ \\
\hline
\end{tabular}

$*_{p}<0.05$ (Student's t-test, experimental groups vs. control group; ANOVA, intergroup comparisons). ns: non-significant; SD: standard deviation. 
No significant differences were observed across groups in mean maternal weight gains from the beginning to the end of gestation. No significant differences were detected in fetal or placental mean weights (Table 2).

Table 2 - Maternal, fetal, and placental weight gains, as measured on day 21 of gestation.

\begin{tabular}{lcccccc}
\hline Group & $\begin{array}{c}\text { Maternal weight gain } \\
\text { (g; mean } \pm 1 \text { SD) }\end{array}$ & $\mathrm{p}^{*}$ & $\begin{array}{c}\text { Fetal weight (g; } \\
\text { mean } \pm 1 \text { SD) }\end{array}$ & $\mathrm{p}^{*}$ & $\begin{array}{r}\text { Placental weight } \\
\text { (g; mean } \pm 1 \text { SD) }\end{array}$ & $\mathrm{p}^{*}$ \\
\hline $\begin{array}{l}\text { I: Control } \\
\begin{array}{l}\text { II: Enoxaparin, } \\
\text { prophylactic dose }\end{array}\end{array}$ & $8.22 \pm 1.32$ & - & $5.62 \pm 0.78$ & - & $0.83 \pm 0.18$ & - \\
$\begin{array}{l}\text { III: Enoxaparin, } \\
\text { therapeutic dose }\end{array}$ & $7.92 \pm 1.51$ & $n s$ & $5.83 \pm 0.62$ & ns & $0.83 \pm 0.22$ & $n s$ \\
$\begin{array}{l}\text { IV: UFH, prophylactic } \\
\text { dose }\end{array}$ & $8.27 \pm 1.25$ & $n s$ & $5.67 \pm 0.55$ & ns & $0.84 \pm 0.17$ & $n s$ \\
$\begin{array}{l}\text { V: UFH, therapeutic } \\
\text { dose }\end{array}$ & $7.94 \pm 1.42$ & $n s$ & $6.01 \pm 0.24$ & ns & $0.81 \pm 0.15$ & $n s$ \\
\hline
\end{tabular}

${ }^{*} p<0.05$ (Student's t-test, experimental groups vs. control; ANOVA, intergroup comparisons). ns: non-significant; SD: standard deviation.

$\mathrm{PSV}, \mathrm{RI}$, and $\mathrm{PI}$ did not show normal distribution on the Shapiro-Wilk test and are expressed as expressed in medians and interquartile differences in Tables 3 and 4.

Comparisons of PSV, RI, and PI medians between each experimental group and controls, as well as across all groups, revealed no significant differences in each type of vessel investigated (Table 3 ).

Comparisons of median VPS, RI, and $\mathrm{PI}$ values for right and left uterine arteries revealed no significant differences between each experimental group and control group, or across groups (Table 4).

Table 3 - Maternal, fetal, and placental weight gains, as measured on day 21 of gestation.

\begin{tabular}{lccccccc}
\hline \multirow{2}{*}{ Vessel } & Index & \multicolumn{7}{c}{ Group } & \multirow{2}{*}{ P $^{*}$} \\
\cline { 3 - 7 } & & $\mathrm{I}$ & $\mathrm{II}$ & $\mathrm{III}$ & $\mathrm{IV}$ & $\mathrm{V}$ & \\
\cline { 2 - 7 } & & $(n=60)$ & $(n=60)$ & $(n=60)$ & $(n=60)$ & $(n=60)$ & \\
\hline MCA & PSV & $6.32 \pm 1.25$ & $7.05 \pm 1.34$ & $6.14 \pm 1.15$ & $6.95 \pm 1.22$ & $6.27 \pm 1.47$ & $\mathrm{~ns}$ \\
& $\mathrm{RI}$ & $0.58 \pm 0.11$ & $0.62 \pm 0.19$ & $0.48 \pm 0.21$ & $0.55 \pm 0.11$ & $0.63 \pm 0.13$ & $\mathrm{~ns}$ \\
& $\mathrm{PI}$ & $1.62 \pm 0.35$ & $1.83 \pm 0.39$ & $1.45 \pm 0.28$ & $1.71 \pm 0.38$ & $1.74 \pm 0.27$ & $\mathrm{~ns}$ \\
\hline DV & $\mathrm{PSV}$ & $10.3 \pm 1.74$ & $11.3 \pm 1.52$ & $15.1 \pm 3.43$ & $12.3 \pm 1.65$ & $11.3 \pm 1.67$ & $\mathrm{~ns}$ \\
& $\mathrm{RI}$ & $0.54 \pm 0.15$ & $0.53 \pm 0.28$ & $0.51 \pm 0.79$ & $0.55 \pm 0.45$ & $0.49 \pm 0.35$ & $\mathrm{~ns}$ \\
& $\mathrm{PI}$ & $1.23 \pm 0.45$ & $1.28 \pm 0.31$ & $1.24 \pm 0.42$ & $1.18 \pm 0.39$ & $1.27 \pm 0.47$ & $\mathrm{~ns}$ \\
\hline UA & $\mathrm{PSV}$ & $10.7 \pm 3.41$ & $10.2 \pm 3.63$ & $11.5 \pm 3.58$ & $9.8 \pm 3.78$ & $11.4 \pm 2.91$ & $\mathrm{~ns}$ \\
& $\mathrm{RI}$ & $0.48 \pm 0.21$ & $0.45 \pm 0.19$ & $0.42 \pm 0.33$ & $0.51 \pm 0.29$ & $0.47 \pm 0.34$ & $\mathrm{~ns}$ \\
& $\mathrm{PI}$ & $1.42 \pm 0.68$ & $1.34 \pm 0.55$ & $1.45 \pm 0.72$ & $1.47 \pm 0.81$ & $1.79 \pm 0.11$ & $\mathrm{~ns}$ \\
\hline
\end{tabular}

MCA: middle cerebral artery; DV: ductus venosus; UA: umbilical artery; PSV: peak systolic velocity (cm/s); RI: resistance index; PI: pulsatility index.

${ }^{*} p<0.05$ (Mann-Whitney, experimental groups vs. control group; Kruskal-Wallis, intergroup comparisons). Medians \pm interquartile difference. ns: non-significant. 
Table 4 - Maternal, fetal, and placental weight gains, as measured on day 21 of gestation.

\begin{tabular}{lccccccc}
\hline Uterine artery & Index & \multicolumn{9}{c}{ Group } & P* \\
\cline { 3 - 7 } & & $\mathrm{I}$ & $\mathrm{II}$ & $\mathrm{III}$ & $\mathrm{IV}$ & $\mathrm{V}$ & \\
\cline { 2 - 7 } & & $(n=10)$ & $(n=10)$ & $(n=10)$ & $(n=10)$ & $(n=10)$ & \\
\hline Right & PSV & $10.3 \pm 1.74$ & $11.3 \pm 1.52$ & $15.1 \pm 3.43$ & $12.3 \pm 1.65$ & $11.3 \pm 1.67$ & $\mathrm{~ns}$ \\
& $\mathrm{RI}$ & $0.54 \pm 0.15$ & $0.53 \pm 0.28$ & $0.51 \pm 0.79$ & $0.55 \pm 0.45$ & $0.49 \pm 0.35$ & $\mathrm{~ns}$ \\
& $\mathrm{PI}$ & $1.23 \pm 0.45$ & $1.28 \pm 0.31$ & $1.24 \pm 0.42$ & $1.18 \pm 0.39$ & $1.27 \pm 0.47$ & $\mathrm{~ns}$ \\
\hline Left & $\mathrm{PSV}$ & $10.3 \pm 1.74$ & $11.3 \pm 1.52$ & $15.1 \pm 3.43$ & $12.3 \pm 1.65$ & $11.3 \pm 1.67$ & $\mathrm{~ns}$ \\
& $\mathrm{RI}$ & $0.54 \pm 0.15$ & $0.53 \pm 0.28$ & $0.51 \pm 0.79$ & $0.55 \pm 0.45$ & $0.49 \pm 0.35$ & $\mathrm{~ns}$ \\
& $\mathrm{PI}$ & $1.23 \pm 0.45$ & $1.28 \pm 0.31$ & $1.24 \pm 0.42$ & $1.18 \pm 0.39$ & $1.27 \pm 0.47$ & $\mathrm{~ns}$ \\
\hline
\end{tabular}

PSV: peak systolic velocity (cm/s); RI: resistance index; PI: pulsatility index.

${ }^{*} p<0.05$ (Mann-Whitney, experimental groups vs. control; Kruskal-Wallis, intergroup comparisons). Medians \pm interquartile difference. $n s$ : non-significant.

\section{Discussion}

Fetal ultrasonography studies conducted with pregnant rats are a promising field in perinatal experimental research, decreasing the need for euthanizing animals for the investigation of fetal development ${ }^{10,11}$. Furthermore, ultrasonography is currently part of routine obstetric procedures ${ }^{2,3,8}$.

International standards have established the middle cerebral artery, ductus venosus, umbilical artery, and uterine arteries as the principal vessels to investigate in fetal ultrasound examinations ${ }^{9}$. Changes in fetal development and placental implantation can be inferred from the observation of abnormal hemodynamics ${ }^{2,8,9}$.

Ultrasonography does not yield the false positive results often associated with other methods involving the use of drugs that effect fetal hemodynamics. In experimental research, the use of non-invasive methods can translate to fewer euthanized animals ${ }^{3,10,11}$. Patterns observed in parametric measurements employing non-invasive techniques such as Doppler velocimetry allow the construction of normality scales that can find utility in the investigation of disorders affecting physiology ${ }^{12}$.

Doppler velocimetry was the technique selected to examine blood flow in maternalfetal vessels after exposure to anticoagulants because these are standard vessels to be monitored for proper fetal health and development, and are part of multivessel surveillance, critical in high-risk pregnancies ${ }^{8}$. Doppler observation of umbilical and uterine arteries allows evaluation of fetal health and maternal risk of pre-eclampsia ${ }^{9}$. Examination of the fetal middle cerebral artery by velocimetry can yield evidence of anemia and, in cases of intrauterine growth restriction, reveal risk of hypoxic lesions. Ductus venosus waveforms help to predict fetal risk and should be taken into account when umbilical artery waveforms appear abnormal. By revealing the condition of placental vasculature in early gestation, Doppler evaluation of the uterine artery is an excellent tool to predict the risk of preeclampsia or intrauterine growth restriction ${ }^{8,9}$.

The importance of ultrasonographic surveillance has been demonstrated in an investigation of blood flow patterns in uterine, umbilical, and middle cerebral arteries, umbilical veins, and ductus venosus in high-risk pregnancy. In the study, 88 pregnant women had these vessels measured until $72 \mathrm{~h}$ before delivery and the results were correlated with adverse outcomes ${ }^{8}$. Correlation was observed between presence of umbilical venous pulsations and low Apgar scores at $5 \mathrm{~min}$, abnormal gasometry, and need for ventilatory support. In addition, changes in umbilical artery 
parameters were correlated with prematurity and admission to a neonatal intensive care unit. Umbilical vein changes, however, did not correlate with adverse perinatal outcomes ${ }^{8}$.

In a study of blood flow in 147 singlebirth pregnancies at risk for preterm labor, the role of Doppler ultrasonography was evaluated at the beginning of the second trimester to measure the risk for intrauterine growth restriction, as well as umbilical coiling index and area selection for umbilical cord testing. It was concluded that measuring the umbilical coiling index in the second trimester can predict smallfor-gestational-age births and can serve as a marker for subsequent growth restriction ${ }^{13}$.

Doppler flow measurements of middle cerebral arteries indirectly determine the degree of oxygenation in the fetal brain, given that fetuses with good oxygenation exhibit high $\mathrm{RI}$ and $\mathrm{PI}$ values for these vessels ${ }^{8,9}$. In the present study, no differences were found in the values of PSV, PI, and $\mathrm{MI}$ of middle cerebral arteries between experimental groups and control group, or across groups, showing that heparin exposure did not interfere with hemodynamics or fetal oxygenation.

In the ductus venosus-a branch of the umbilical artery that carries oxygenated blood under pressure to the left atrium through the right atrium and foramen ovalecentral venous pressure gradient is measured indirectly. Ventricular systole (S), ventricular diastole (D), and atrial systole (A) waves are all positive. In situations of hypoxia with increased cardiac preload, the ductus venosus exhibits an elevated PI. In cases of severe hypoxia with myocardial impairment, A-waves tend to disappear or appear reversed, indicating reversed flow to the ductus venosus ${ }^{8,9,12}$. In the present study, no changes in wave morphology were observed, and comparisons of PSV, PI, and $\mathrm{RI}$ values revealed no significant differences between heparin-exposed groups and control group, or across groups.

In the umbilical arteries, increased $\mathrm{RI}$ or $\mathrm{PI}$ values indicate poor placental functioning ${ }^{8,9,12}$. In the present sample, no significant differences in these indices were observed among the groups.

Following evaluation of these vessels, examining uterine artery flow can reveal the condition of placental implantation ${ }^{9}$. In normal uterine artery flow resulting from adequate placental implantation and trophoblast invasion, findings of $\mathrm{RI}$ or $\mathrm{PI}$ values that are elevated for gestational age indicate increased risk of intrauterine growth restriction and preeclampsia, owing to inadequate placentation. Evaluation of these parameters is typically performed at around 20 gestational weeks, although evaluation from 26 gestational weeks onwards - a period when trophoblast migration is complete-has been advocated ${ }^{8,9}$. In the present study, no changes in uterine arteries were expected, since improved placental adhesion and trophoblastic invasion had been reported for female rats exposed to low-molecular-weight heparin ${ }^{6,7}$. In fact, no significant differences in Doppler velocimetry indices were observed among groups in the present sample.

Widely employed as a diagnostic tool and highly relevant in fetal health surveillance ${ }^{3}$, ultrasonography constitutes a reliable diagnostic resource. Exposure time, however, may require careful control, since changes in fetal intestinal ${ }^{4}$, liver $^{5}$ and brain tissues ${ }^{14,15}$ as a result of tissue heating have been reported for rats subjected to prolonged exposure to ultrasound.

For the present investigation, nonfractionated and low-molecular-weight heparins were selected for administration in prophylactic and therapeutic doses ${ }^{16}$. Some drugs can cause hemodynamic changes, whether directly or indirectly ${ }^{12,17-19}$.

In the middle cerebral artery, the likelihood of changes in flow patterns is high in cases of poor cerebral formation or hypoxia ${ }^{8}$. This parameter is therefore useful in the investigation of teratogenicity and brain development in studies involving 
drug experimentation. The effects of drugs detrimental to placentation can be measured by examining uterine artery flow. Heparins have been experimentally shown $n^{6,7}$ to improve trophoblastic invasion, a beneficial effect that supports heparin use by thrombophilic pregnant women, and also as a prophylactic measure to prevent placental thrombosis or poor placentation and consequent fetal loss or miscarriage. No changes in Doppler flowmetry patterns of the uterine arteries and umbilical vessels were therefore expected, which is consistent with the absence of significant differences among the groups in the present study.

Monitoring Doppler velocimetry parameters is a suitable approach in largescale studies designed to identify indices and/or markers with utility in early diagnosis and interventions for preventing undesirable outcomes ${ }^{20}$.

\section{- Conclusions}

No differences in Doppler velocimetry measurements were observed for median PSV, $\mathrm{RI}$, or PI values in fetal middle cerebral arteries, ductus venosus, or umbilical arteries in healthy pregnant Wistar rats exposed to enoxaparin and UFH administered in prophylactic and therapeutic doses.

\section{References}

1. Kearon C, Akl EA, Ornelas J, Blaivas A, Jimenez $D$, Bounameaux $H$, Huisman $M$, King CS, Morris TA, Sood N, Stevens SM, Vintch JRE, Wells P, Woller SC, Moores L. Antithrombotic Therapy for VTE Disease: CHEST Guideline and Expert Panel Report. Chest. 2016;149(2):315-52. doi: 10.1016/j. chest.2015.11.02.

2. Maiz N, Valencia C, Kagan KO, Wright D, Nicolaides KH. Ductus venosus Doppler in screening for trisomies 21, 18 and 13 and Turner syndrome at 11-13 weeks of gestation. Ultrasound Obstet Gynecol.
2009;33:512-7. doi: 10.1002/uog.6330.

3. DuckFA. Hazards, risksand safety of diagnostic ultrasound. Med Eng Phys. 2008;30:133848. doi: 10.1016/j.medengphy.2008.06.002.

4. Miller DL, Thomas RM. Heating as a mechanism for ultrasonically-induced petechial hemorrhage in mouse intestine. Ultrasound Med Biol. 1994;20:493-503. PMID: 7941106.

5. Pellicer B, Herraiz S, Ta'Boas E, Felipo V, Simon C, Pellicer A. Ultrasound bioeffects in rats: quantification of cellular damage in the fetal liver after pulsed Doppler imaging Ultrasound Obstet Gynecol. 2011;37:643-8. doi: 10.1002/uog.8842.

6. Erden O, Imir A, Guvenal T, Muslehiddinoglu $A$, Arici S, Celtin M. Investigation of the effects of heparin and low molecular weight heparin on E-cadherin and laminin expression in rat pregnancy by immunohistochemistry. Hum Reprod. 2006 Nov;21(11):3014-8. PMID: 16997938. 22.

7. Zhang $\mathrm{Y}$, Zhong $\mathrm{M}$, Liu F. Low molecular weight heparin inhibits cell apoptosis in the placenta of rats with preeclampsia-like symptoms. Nan Fanq Yi Ke Da Xue Xue Bao. 2012 Jun;32(6):862-6. PMID: 22699071.

8. Cheema R, Bayoumi MZ, Gudmundsson S. Multivascular Doppler surveillance in high risk pregnancies. J Matern Fetal Neonatal Med. 2012 Jul;25(7):970-4. doi: 10.3109/14767058.2011.602141.

9. Kalache KD, Dückelmann AM. Doppler in obstetrics: beyond the umbilical artery. Clin Obstet Gynecol. 2012 Mar;55(1):288-95. doi: 10.1097/GRF.0b013e3182488156.

10.Stasinopoulou M, Mantziaras G, Paronis $E$, Balafas $E$, Lelovas $P$, Samara $A$, Kostomitsopoulos $\mathrm{N}$. Use of real-time ultrasonography as an alternative method for early detection, confirmation and evaluation of rat pregnancy. Ultrasound Med Biol. 2014 Jun;40(6):1372-8. doi: 10.1016/j. ultrasmedbio.2013.11.016.

11.Hernandez-Andrade $E$, Ahn $H$, Szalai G, Korzeniewski SJ, Wang B, King $M$, Chaiworapongsa T, Than NG, Romero R. Evaluation of utero-placental and fetal hemodynamic parameters throughout 
gestation in pregnant mice using highfrequency ultrasound. Ultrasound Med Biol. 2014 Feb;40(2):351-60. doi: 10.1016/j. ultrasmedbio.2013.09.026.

12.Royston P, Wright EM. How to construct 'normal ranges' for fetal variables. Ultrasound Obstet Gynecol. 1998;11:30-8. doi/10.1046/j.1469-0705.1998.11010030.x.

13.Degani S, Leibovich Z, Shapiro I, Gonen $R$, Ohel G. Early second-trimester low umbilical coiling index predicts small-forgestational-age fetuses. J Ultrasound Med. 2001;Nov;20(11):1183-8. PMID: 11758023.

14.Li P, Wang PJ, Zhang W. Prenatal exposure to ultrasound affects learning and memory in young rats. Ultrasound Med Biol. 2015 Mar;41(3):644-53. doi: 10.1016/j. ultrasmedbio.2014.09.015.

15.Yang FY, Lin GL, Horng SC, Chen RC. Prenatal exposure to diagnostic ultrasound impacts blood-brain barrier permeability in rats. Ultrasound Med Biol. 2012 Jun;38(6):10517. doi: 10.1016/j.ultrasmedbio.2012.01.017.

16.Erkens PM, Prins $\mathrm{MH}$. Fixed dose subcutaneouslow molecular weight heparins versus adjusted dose unfractionated heparin for venous thromboembolism. Cochrane Database Syst Rev. 2010 Sep;8(9):CD001100. doi: 10.1002/14651858.CD001100.pub3.

17.Yamamoto Y, Thebaud B, Vadivel A, Eaton F,
Jain V, Hornberger LK. Doppler parameters of fetal lung hypoplasia and impact of sildenafil. Am J Obstet Gynecol. 2014 Sep;211(3):263. e1-8. doi: 10.1016/j.ajog.2014.03.013.

18.Ekin A, Gezer C, Solmaz U, Taner CE, Ozeren M, Dogan A, Uyar I. Effect of antenatal betamethasone administration on Doppler velocimetry of fetal and uteroplacental Vessels: a prospective study. J Perinat Med. 2016 Mar;44(2):243-8. doi: 10.1515/jpm2015-0194.

19.Galan HL, Rigano S, Chyu J, Beaty B, Bozzo $M$, Hobbins JC, Ferrazzi E. Comparison of low- and high-altitude Doppler velocimetry in the peripheral and central circulations of normal fetuses. Am J Obstet Gynecol. 2000 Nov;183(5):1158-61. doi: 10.1067/ mob.2000.109043.

20.Spencer R, Ambler G, Brodszki J, Diemert A, Figueras F, Gratacós E, Hansson SR, Hecher K, Huertas-Ceballos A, Marlow N, Marsál $K$, Morsing E, Peebles D, Rossi C, Sebire NJ, Timms JF, David AL; EVERREST Consortium. EVERREST prospective study: a 6-year prospective study to define the clinical and biological characteristics of pregnancies affected by severe early onset fetal growth restriction. BMC Pregnancy Childbirth. 2017 Jan;17(1):43. doi: 10.1186/s12884-0171226-7.

\section{Correspondence:}

Flavio Renato de Almeida Senefonte

Faculdade de Medicina

Secretaria do Programa de Pós-graduação em

Saúde e Desenvolvimento-UFMS

Avenida Senador Felinto Muller, s/n

79070-900 Campo Grande - MS Brasil

Tel.: (55 67)3345-7355

flaviosenefonte@gmail.com

Received: Jan 18, 2017

Review: Mar 17, 2017

Accepted: Apr 20, 2017
Conflict of interest: none

Financial source: none

${ }^{1}$ Research performed at Laboratory of Experimental Surgery, Department of Clinical Surgery, School of Medicine, Universidade Federal de Mato Grosso do Sul (UFMS), Campo Grande-MS, Brazil. Part of PhD degree thesis, Postgraduate Program in Health and Development of Midwestern Brazil. Tutor: Ernesto Antonio Figueiró-Filho. 